\title{
Explaining variability in the production of seed and allergenic pollen by invasive Ambrosia artemisiifolia across Europe
}

\author{
Suzanne T. E. Lommen - Caspar A. Hallmann • Eelke Jongejans • \\ Bruno Chauvel • Melinda Leitsch-Vitalos • Alla Aleksanyan • Peter Tóth • \\ Cristina Preda • Maja Šćepanović • Huseyin Onen • Barbara Tokarska-Guzik • \\ Paulina Anastasiu • Zita Dorner • Annamária Fenesi • Gerhard Karrer • \\ Katalin Nagy • Gyula Pinke • Viktor Tiborcz • Gergely Zagyvai • \\ Mihály Zalai • Gabriella Kazinczi • Robert Leskovšek • Danijela Stešević • \\ Guillaume Fried $\cdot$ Levani Kalatozishvili $\cdot$ Andreas Lemke $\cdot$ Heinz Müller-Schärer
}

\begin{abstract}
To better manage invasive populations, it is vital to understand the environmental drivers underlying spatial variation in demographic performance of invasive individuals and populations. The invasive common ragweed, Ambrosia artemisiifolia, has severe adverse effects on agriculture and human health, due to its vast production of seeds and
\end{abstract}

Electronic supplementary material

S. T. E. Lommen $(\bowtie) \cdot$ C. Preda $\cdot$ H. Müller-Schärer Department of Biology, University of Fribourg, Chemin du Musée 10, Fribourg, Switzerland

e-mail: suzannelommen@hotmail.com

C. A. Hallmann · E. Jongejans

Institute for Water and Wetland Research, Radboud

University, Heyendaalseweg 135, 6525 AJ Nijmegen,

The Netherlands

\section{B. Chauvel}

Agroécologie, AgroSup Dijon, INRA, Univ. Bourgogne Franche-Comté, 21000 Dijon, France

M. Leitsch-Vitalos · G. Karrer

Institute of Botany, University of Natural Resources and Life Sciences, Gregor-Mendel-Straße 33, 1180 Vienna, Austria allergenic pollen. Here, we identify the scale and nature of environmental factors driving individual performance of A. artemisiifolia, and assess their relative importance. We studied 39 populations across the European continent, covering different climatic and habitat conditions. We found that plant size is the most important determinant in variation of per-capita seed and pollen production. Using plant volume as a measure of individual performance, we found that the local environment (i.e. the site) is far more influential for plant volume (explaining $25 \%$ of all spatial

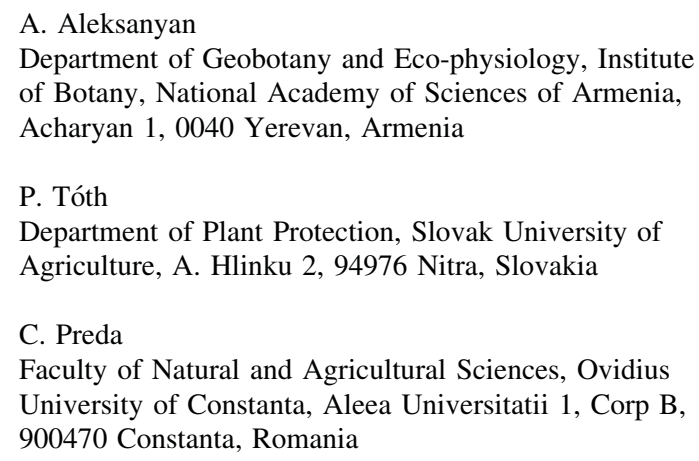


variation) than geographic position (regional level; $8 \%$ ) or the neighbouring vegetation (at the plot level; $4 \%)$. An overall model including environmental factors at all scales performed better (27\%), including the weather (bigger plants in warm and wet conditions), soil type (smaller plants on soils with more sand), and highlighting the negative effects of altitude, neighbouring vegetation and bare soil. Pollen and seed densities varied more than 200-fold between sites, with highest estimates in Croatia, Romania and Hungary. Pollen densities were highest on arable fields, while highest seed densities were found along infrastructure, both significantly higher than on ruderal sites. We discuss implications of these findings for the spatial scale of management interventions against A. artemisiifolia.

Keywords Ragweed - Environmental drivers · Invasive alien plant - Demographic performance . Spatial variation

\section{Introduction}

How well invasive alien populations perform locally depends on how they respond to their new environment (Richardson and Pyšek 2012). Different

\section{H. Onen}

Department of Plant Protection, Faculty of Agriculture, Gaziosmanpasa University, 60240 Tokat, Turkey

\section{B. Tokarska-Guzik}

Department of Botany and Nature Protection, Faculty of Biology and Environmental Protection, University of Silesia in Katowice, Jagiellonska 28, 40-032 Katowice, Poland

\section{P. Anastasiu}

Department of Botany and Microbiology \& Botanic Garden "D. Brandza", University of Bucharest, Intr. Portocalelolor 1-3, 060101 Bucharest, Romania

\section{Z. Dorner · M. Zalai}

Plant Protection Institute, Szent István University, Pater K. str. 1, Gödöllö 2100, Hungary

\section{A. Fenesi}

Hungarian Department of Biology and Ecology, BabeşBolyai University, Republicii str. 42,

400015 Cluj-Napoca, Romania environmental factors may act at different spatial scales (Jongejans et al. 2010), and assessing the relative importance of these scales will inform whether general management strategies are applicable or if a case-by-case approach is needed (Pauchard and Shea 2006). Invader performance is therefore ideally assessed at multiple spatial scales and in various invaded habitat types within a broad distributional range, but this has only occasionally been done (Pauchard and Shea 2006; Traveset et al. 2008). Performance in the field may be measured by abundance and individual performance-related demographic traits such as survival, growth and fecundity. Such field data can be used to evaluate whether environmental factors that were previously identified by experiments under controlled conditions are indeed important under natural situations, where multiple ecological and genetic factors interact (Colautti et al. 2014).

We here use invasive populations of common ragweed, Ambrosia artemisiifolia L. (Asteraceae) on the European continent to identify what environmental factors drive A. artemisiifolia performance, and at what spatial scale. The species originates from North America but has become a widespread invader on several continents. It is an annual pioneer species that can grow in a wide range of habitat types and climates

K. Nagy · G. Pinke

Faculty of Agricultural and Food Sciences, Széchenyi István University, Vár 2, Mosonmagyaróvár 9200, Hungary

V. Tiborcz - G. Zagyvai

Institute of Botany and Nature Conservation, Faculty of Forestry, University of West Hungary, Bajcsy-Zs. str. 4, Sopron 9400, Hungary

\section{G. Kazinczi}

Institute of Plant Science, Faculty of Agricultural and Environmental Sciences, Kaposvár University, Guba S. str. 40, Kaposvár 7400, Hungary

\section{R. Leskovšek}

Agricultural Institute of Slovenia, Hacquetova ulica 17, 1000 Ljubljana, Slovenia

\section{Stešević}

Biology Department, Faculty of Natural Sciences and Mathematics, University of Montenegro, Džordža Vašingtona bb, 81000 Podgorica, Montenegro 
(Essl et al. 2015). While germination from the longlasting seedbank can occur over several months in spring and summer, reproductive structures are formed after mid-summer. The monoecious species produces pollen that is wind-dispersed and are an important aeroallergen with severe implications for human health (Smith et al. 2013). After pollen production plants produce vast amounts of seeds that fall straight to the ground in autumn and can result in high plant densities in following years, which can reduce crop yields (Kazinczi et al. 2009). Dispersal of the seeds is mainly due to human activity (Chapman et al. 2016; Karrer et al. 2011; Vitalos and Karrer 2009; von der Lippe et al. 2013), but waterways are also reported to facilitate dispersal (Fumanal et al. 2007b). Climate change is expected to favour the spread of A. artemisiifolia (Chapman et al. 2014; Cunze et al. 2013; Essl et al. 2015) and to aggravate its health impact (Hamaoui-Laguel et al. 2015). Current chemical and physical management strategies against the species applied in Europe aim at reducing plant biomass, pollen or seed production, but are not applicable in many non-crop habitats and often not effective in long-term control (Buttenschøn et al. 2009; Karrer et al. 2011).

To effectively manage A. artemisiifolia in Europe, it is vital to understand how the natural environment affects demographic performance of this invader in terms of amounts of pollen and seeds produced. An earlier study in France found 30-fold variation in the seasonal pollen production per plant, and 18-fold variation in seed numbers among five sites, with higher values on crop fields than on wasteland (Fumanal et al. 2007a). A recent field survey in various ruderal habitat types across Western Europe found up to 10 -fold variation in average seed production per plant among twelve populations, but failed in

\section{G. Fried}

Laboratoire de la Santé des Végétaux, Unité entomologie et plantes invasives, Anses, 755 avenue du Campus Agropolis, 34988 Monferrier-sur-Lez, France

\section{Kalatozishvili}

Institute of Botany, Ilia State University, Botanical Str. 1, 0105 Tbilisi, Georgia

\section{A. Lemke}

Department of Ecology, Chair of Plant Ecology and

Ecosystem Science, Technische Universität Berlin,

Rothenburgstr. 12, 12165 Berlin, Germany attributing this to any environmental factor (Ortmans et al. 2016). We conducted a field survey of 39 populations of $A$. artemisiifolia covering a much broader latitudinal and longitudinal gradient (over 1000 and $3000 \mathrm{~km}$, respectively), as well as most of its important habitat types (Fig. 1). In need of a proxy for individual pollen and seed production that can easily be measured in the field, we first assessed the use of plant volume for this purpose (Fumanal et al. 2007a). Based on literature review, we then assessed a set of a priori environmental factors likely to affect performance of individual A. artemisiifolia at different spatial scales. Specifically, we asked which environmental factors, and at what scale, best explain spatial variation in A. artemisiifolia plant volume across the European continent? We finally used our data to estimate pollen and seed production per surface area and looked at patterns in variation across habitat types and countries.

\section{Materials and methods}

A priori selection of environmental factors and their spatial scales

Since we aimed to use plant volume of A. artemisiifolia as a measure of its performance, we started by conducting a literature survey on environmental factors influencing its size or growth. We first selected environmental factors acting in the direct neighbourhood of the plant. Both interspecific and intraspecific competition reduce performance of $A$. artemisiifolia in field and greenhouse experiments (Leskovsek et al. 2012a, b; MacDonald and Kotanen 2010; Patracchini et al. 2011). The vegetation can be spatially heterogeneous, and neighbours are likely the most important competitors. We therefore selected vegetation cover, light competition and Ambrosia density to be assessed at a scale of only $0.5 \mathrm{~m} \times 0.5 \mathrm{~m}$ (hereafter 'plot'). We then selected variables acting at the local scale (i.e. at the scale of the site in which a population grows). Experimentally increased temperature and water supply have been found to enhance aboveground growth of $A$. artemisiifolia (Deen et al. 1998; Leskovsek et al. 2012b; Skálová et al. 2015), while the biomass of plants from the French Alps grown in a common garden was positively correlated with the temperature of the provenance (Gallien et al. 2016). We therefore 


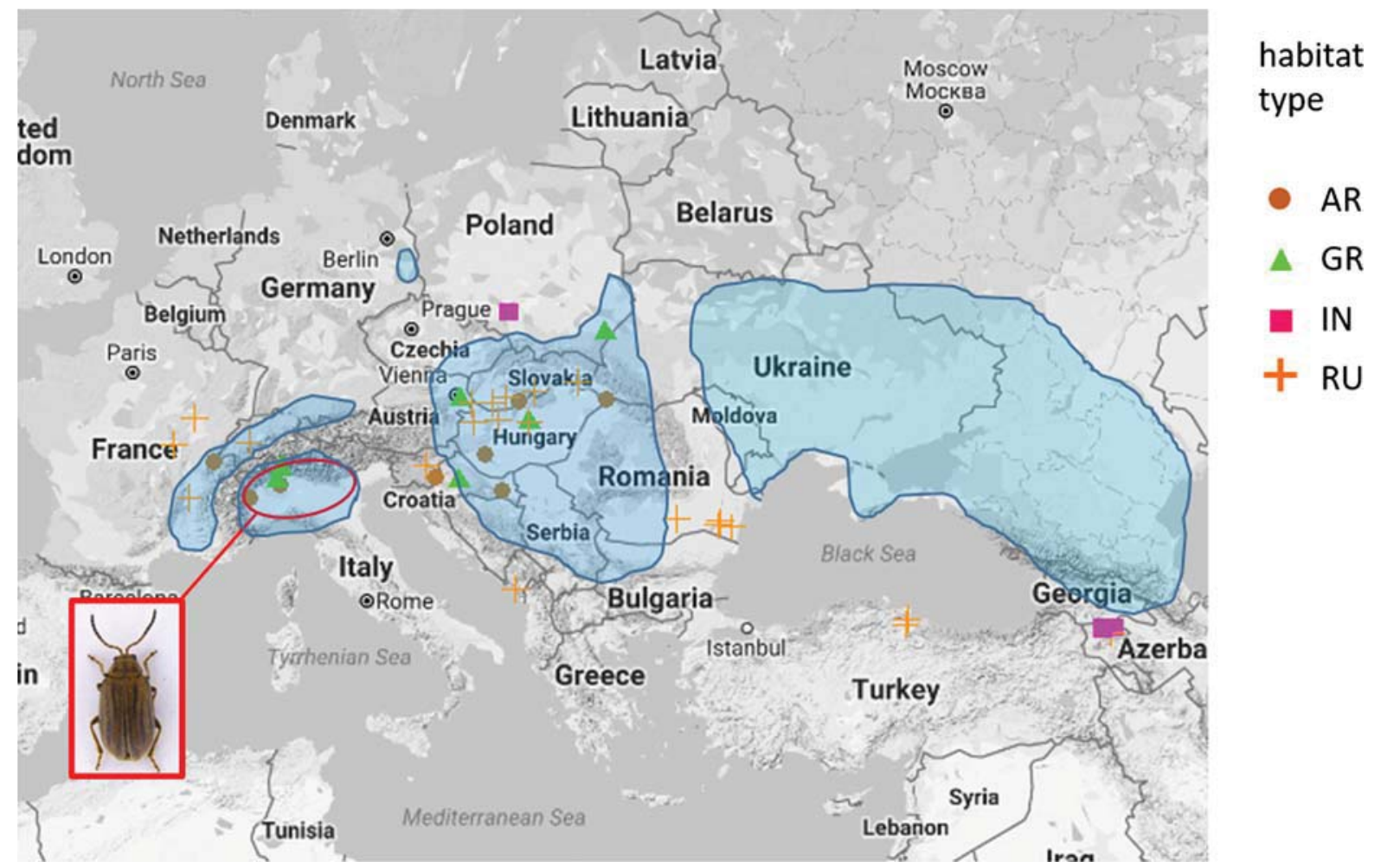

Fig. 1 Location of the 39 study sites used for the analyses, with symbols according to the habitat type ( $A R$ arable, $G R$ grassland, $I N$ infrastructure, $R U$ ruderal). Areas shaded in blue indicate areas known to be heavily colonized by $A$. artemisiifolia (numerous and abundant stands) and with high levels of

expected better performance at locations with warmer growing seasons (more growing degree days) and higher levels of precipitation, and collected local weather data. The species grows on a wide variety of habitat types and soil textures (Essl et al. 2015; Fumanal et al. 2008), which may result in differential demographic performance. We expected plants to grow taller on arable land because of likely higher nutrient levels (Fumanal et al. 2007a; Karrer et al. 2011), but had no a priori expectations about the effect of other habitat types and soils because literature on this issue was lacking. Several regions in Europe are recently colonised by the exotic ragweed leaf beetle Ophraella communa LeSage (Müller-Schärer et al. 2014). This leaf feeder preferably feeds on $A$. artemisiifolia and has the potential to reduce its growth and reproduction (Zhou et al. 2014), and is a candidate biological control agent of A. artemisiifolia in Europe (Lommen et al. 2017). We expected negative effects of this beetle on the performance of allergies and/or damage to agriculture (based on Chapman et al. 2016; Déchamp et al. 2009; Essl et al. 2015), while the red oval connected to the picture of the ragweed leaf beetle Ophraella communa indicates the area colonized by this candidate biocontrol agent (based on Lommen et al. 2017)

A. artemisiifolia and assessed its presence at the sites. Finally, geographical position is related to day length, length of the growing season, and temperature, and may result in regional patterns. Common garden experiments indeed found reduced biomass with increasing latitude (Leiblein-Wild and Tackenberg 2014). We therefore selected latitude, longitude and altitude as environmental factors representing regional factors. All selected variables at the three different scales ("plot", "site" and "regional") were included in the study design.

\section{Study sites}

We exclusively used sites with established populations of A. artemisiifolia, constituting more than 200 individuals in an area of at least $30 \mathrm{~m}^{2}$. Different climatic conditions (regional factors) were included by covering as much of the geographic and altitudinal range on the European continent as possible. In order 
to assess site-specific conditions, we selected sites without clear environmental gradients. We aimed to cover the most important habitat types of A. artemisiifolia. As we focussed on non-human environmental drivers, we only included sites without management of ragweed, but accepted general vegetation management by mowing and grazing (but not herbicides) to include habitat types such as road and railway sides and grasslands. These interventions only took place outside the growing season of A. artemisiifolia to avoid direct damage to them. Sites with disturbance of the soil (e.g. cultivated fields) and immigration or emigration of seeds (e.g. flooded river banks) were excluded for the sake of our long-term objective to quantify the demography of standing populations including the soil seed bank. Complying with these selection criteria, a total of 45 sites were selected, from the most southern and eastern population in Armenia over a latitudinal gradient up to northern Germany and along a longitudinal gradient west to France (Fig. 1). This selection covered most of the bioclimatic range of this species on the European continent (Table S1).

All data were collected in 2014. Study sites were classified as one of the following five habitat types: arable (AR, formerly cultivated land, but fallow land at the time of the study), grasslands (GR), infrastructure (IN, linear sites along and up to $10 \mathrm{~m}$ away from roads or railways), riparian (RI, former river banks currently non-flooded), ruderal (RU, unmanaged currently not human-disturbed land not belonging to any of the above categories, e.g. gravel pits, waste deposits, hunting terrains, terrains in urban or industrial areas). The class of soil texture was determined according to the 12 classes defined by the USDA (http:// www.nrcs.usda.gov/wps/portal/nrcs/detail/soils/survey/ ?cid=nrcs142p2_054167) from a mixed sample of ten $100 \mathrm{ml}$ subsamples of the upper $5 \mathrm{~cm}$ of soil in which $A$. artemisiifolia seeds can germinate (Kazinczi et al. 2008). Four of the sites lay in Northern Italy and Southern Switzerland, the area colonized by the beetle Ophraella communa. The presence of this beetle was confirmed for all the four sites. For each site, daily weather data of 2014 were obtained from the nearest weather station (2-89 $\mathrm{km}$ away, mean $=25 \mathrm{~km}$ away) through the observation network 'Global Summary of the Day', part of the World Weather Watch Programme within the World Meteorological Organization. Six sites had to be excluded from the analysis since their plants were destroyed during the season by unexpected management or flooding. Table 1 and Fig. 1 provide an overview of the remaining 39 sites, which does not include any riparian habitat type anymore.

Plots within sites

In order to detect environmental drivers at our smallest spatial scale ("plot-level"), we created plots of $0.5 \mathrm{~m}$ by $0.5 \mathrm{~m}$ within each site. Since competition effects are important in the early developmental stages of $A$. artemisiifolia (Fenesi et al. 2014), we started the study once most plants were expected to have established, but were still in an early vegetative stage (ca. June, but the exact date differed according to phenology at the specific site). Ambrosia artemisiifolia can be distributed patchily within sites (Fumanal et al. 2008), allowing for the detection of potential intraspecific density-dependent effects. We therefore placed between 12 and 15 plots semi-randomly at each site capturing the entire range of $A$. artemisiifolia densities found within the site (with a minimum distance of $1 \mathrm{~m}$ between them and from the outside border of the site). For each plot, we counted the total number of established A. artemisiifolia. As a general proxy for competition we estimated the fraction of bare soil within each plot as the fraction of the plot not covered by any living vegetation (bare soil hence included dead vegetation, litter, and rocks). As a proxy of interspecific competition we estimated the fraction covered by all vegetation other than $A$. artemisiifolia. We visually classified how much the $A$. artemisiifolia plants in a plot were on average suffering from interspecific competition for light into three classes: (1) not, when A. artemisiifolia was taller than the other species; (2) somewhat, when they were surrounded by other species of similar or taller height but was not entirely overshadowed; (3) a lot, when they were overshadowed. We re-assessed the total number of $A$. artemisiifolia for each plot at seed set (ca. September).

\section{Plant performance}

Upon establishment of the plots, we tagged randomly chosen A. artemisiifolia individuals in each plot, aiming for an average of 10 per plot. The performance of the surviving tagged plants was assessed at seed set when both male and female inflorescences are (still) present (ca. September, but the exact date was site- 


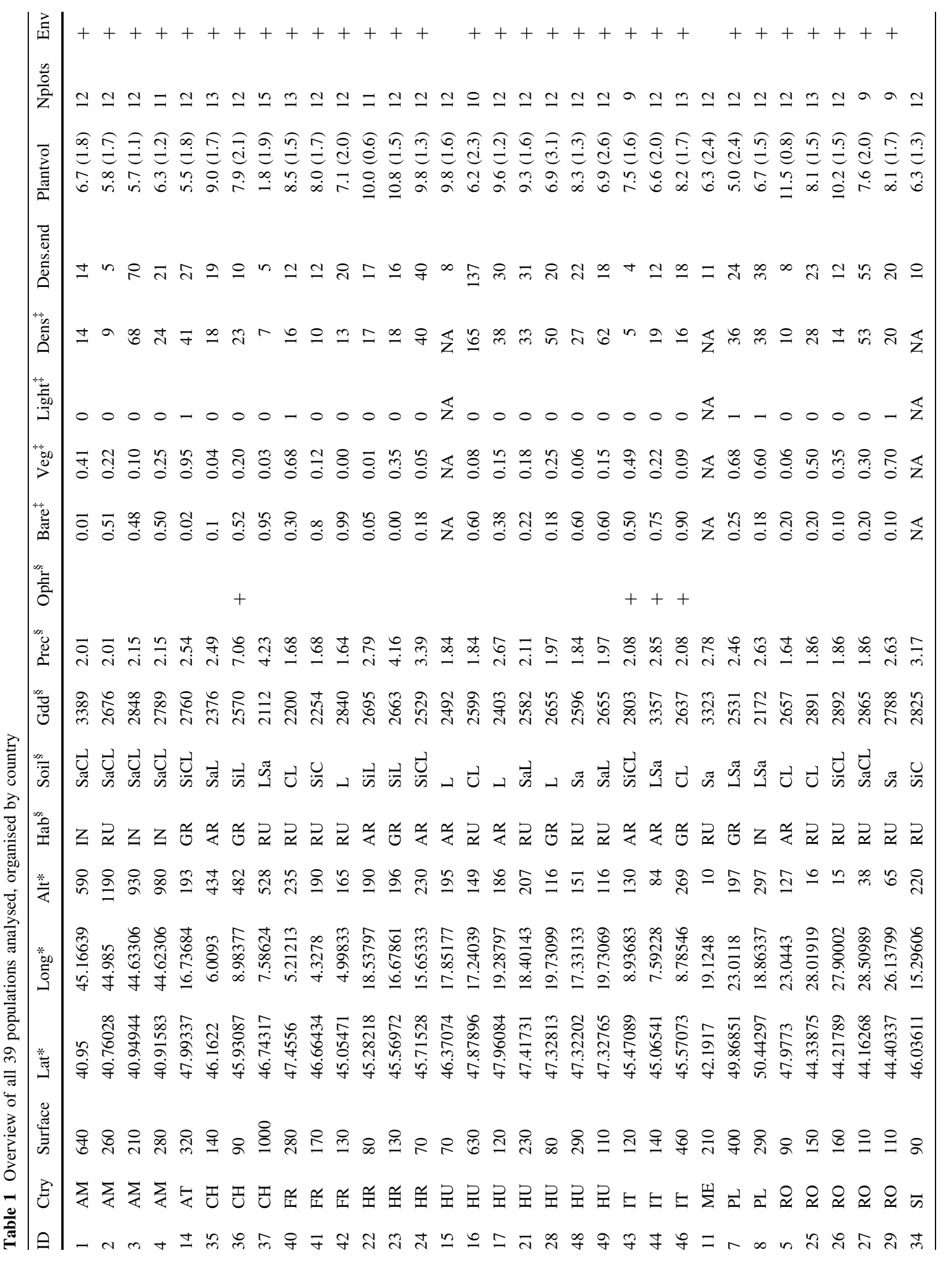




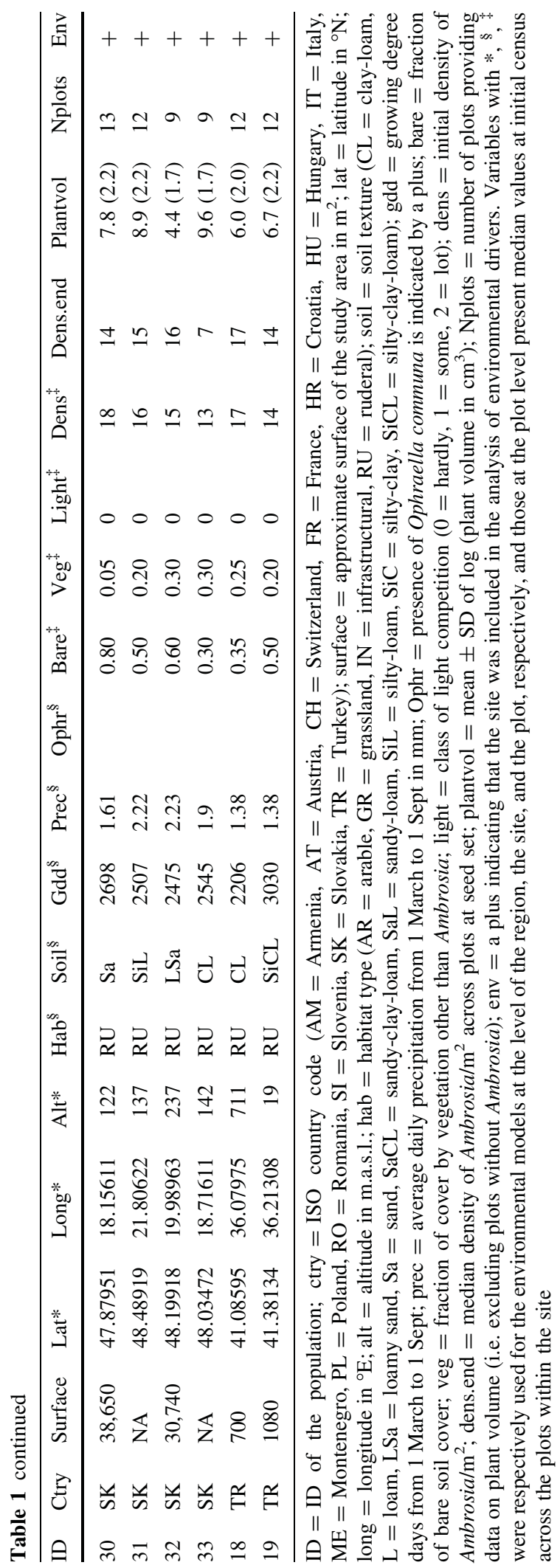

specific). We assessed maturation (possessing any reproductive tissue), and measured their maximum height and maximum width in up-held position. In three of the sites, the study only commenced at that time (i.e. plot-level environmental variables earlier in the season are unavailable, see Table 1). To quantify pollen and seed production without disturbing the dynamics in the plots for future demographic research, we sampled 21 mature $A$. artemisiifolia outside the plots within each site, with sizes representative of the site. We measured their height and width as described above. Additionally, we measured the total length of the racemes bearing male inflorescences of each sampled plant as a proxy for the amount of pollen produced. As a measure of the maximum potential seed production we counted the total number of female structures formed by each sampled plant: either by summing all individual flowers/seeds formed (one flower produces one seed; $\mathrm{N}=24$ sites), or by summing the number of flower heads formed (clusters of flowers/seeds; $\mathrm{N}=15$ sites). Finally, these plants were dried to determine their aboveground dry biomass. The volume of each surviving or sampled A. artemisiifolia was calculated as the content of a cylinder with maximum plant height as height, and 0.25 times maximum plant width as radius. Plant volume, biomass, raceme length, and number of female structures were log-transformed prior to analysis to represent the multiplicative process of growth.

Environmental factors

The soil texture classes were recoded into continuous variables representing the average fractions of clay and sand according to the USDA soil texture triangle. The presence or absence of Ophraella on a site was represented by a binomial factor. For each site, we calculated the cumulative growing degree days (GDD) and the average daily precipitation over the growing season of $A$. artemisiifolia, taken from 1 March up to and including 1 September 2014. We used data from the nearest weather station, and temperatures at the site were estimated by correcting for the altitudinal difference with the weather station (range $=1-1119 \mathrm{~m}, \quad$ mean $=151 \mathrm{~m}$, median difference $=33 \mathrm{~m}$ difference in altitude) following the International Standard Atmosphere model (a drop in $6.5^{\circ} \mathrm{C}$ for every $1000 \mathrm{~m}$ increase in altitude). When temperature data were missing for single days, they 
were interpolated from the five preceding and five subsequent days. Daily GDD was then calculated as the degrees Celsius by which the average of the maximum and minimum temperature at the site exceeded the base temperature of $2{ }^{\circ} \mathrm{C}$ [the threshold for $A$. artemisiifolia germination in the European invaded range (Leiblein-Wild et al. 2014)].

\section{Models of size-dependent reproduction}

All computations and analyses were performed in $\mathrm{R}(\mathrm{R}$ Core Team 2014). We used the data of the sampled plants from all 39 sites to analyse pollen and seed production as a function of plant volume and biomass (Fumanal et al. 2007a). We constructed four generalized mixed effect models for all combinations of raceme length or female structures as response variable, and volume or biomass as fixed effect (Table S2), all log-transformed. When female structures were the response variable, the type of female structures counted (individual seeds or flower heads) was included as a fixed effect. Site was always included as a random effect on both the intercept and the slope, and we used Gaussian distribution of errors (on the log scale) and Restricted Maximum Likelihood to fit the models.

\section{Models of plant volume}

We used the data from the survived, individually tagged plants within the plots to examine the variation in log-transformed plant volume within and across sites (see Table 1 for the number of plots included in the analysis). To quantify the amount of spatial variation, we conducted a variance component analysis, using data from all 39 sites in a linear model with plant volume as response, and plots nested within sites as random effect. We then modelled variation in individual plant volume as a function of environmental variables, using the subset of the 36 sites with complete data of all environmental factors recorded (indicated in column 'env' in Table 1). The general procedure concerned the construction of linear mixedeffect models with individual plant volume as the response variable, environmental variables as the fixed factors, and plots nested within sites as a random effect on the intercept. They were fitted with an Identity link function with Gaussian error distribution, Maximum Likelihood, and the optimizing algorithm "optim".
We created four models, each with a different set of environmental factors as fixed effects: three representing the different spatial scales "regional", "site", and "plot", and a fourth, "total", including all environmental factors of all three spatial scales. The "regional" factors included those related to geographic location (latitude, longitude and altitude). The "site" factors comprised all other site-specific variables that were distributed patchily in space (habitat type, fraction of clay in the soil, fraction of sand in the soil, GDD, precipitation, the interaction GDD-precipitation, and Ophraella presence). The "plot" variables were those measured at the plot level early in the season when plants were still young (Ambrosia density, bare soil, other vegetation, and light competition). All environmental factors were scaled to a mean of zero and a standard deviation of one, after which no collinearity occurred in any of the four models (usdm package in R) (Naimi 2015). All four models were then subjected to stepwise model selection by AIC with both forward and backward direction of selection (Venables and Ripley 2002), resulting in four reduced models. For all the four full and four reduced models, we calculated the marginal $R^{2}$ (representing the variance explained by the fixed factors alone) and conditional $\mathrm{R}^{2}$ (the variance explained by the fixed and random factors) as an indication of their fit (Nakagawa and Schielzeth 2013).

Models of per-area pollen and seed production

For all 39 sites, we combined observed plant density, maturity, and plant volume at seed set with the sitespecific models on volume-dependent reproduction to estimate the total number of pollen and seeds produced per $\mathrm{m}^{2}$. Estimates of pollen per $\mathrm{m}^{2}$ were obtained for each plot applying the formula pollen $=d * f * v *$ $r * m f h * p * m$, where $d$ is the observed density of living $A$. artemisiifolia in the plot at seed set; $f$ is the fraction of living plants that had matured (fixed at the average across our entire data set: 0.97); $v$ is the average volume per plant in that plot; $r$ is the fitted site-specific mean raceme length in $\mathrm{cm}$ per unit volume as predicted by the linear regression model of racemes on volume; $m f h$ is the number of male flower heads per $\mathrm{cm}$ raceme (fixed at 6.2, as calculated from counts of 100 samples of $2 \mathrm{~cm}$ raceme from two Italian sites); $p$ is the number of pollen grains per flower head [fixed at 421,875, from Weryszko- 

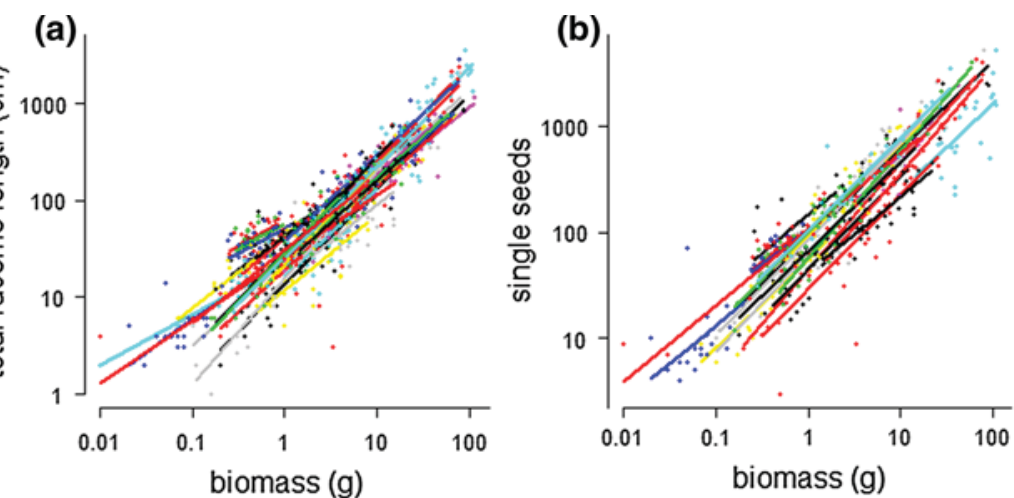

(d)

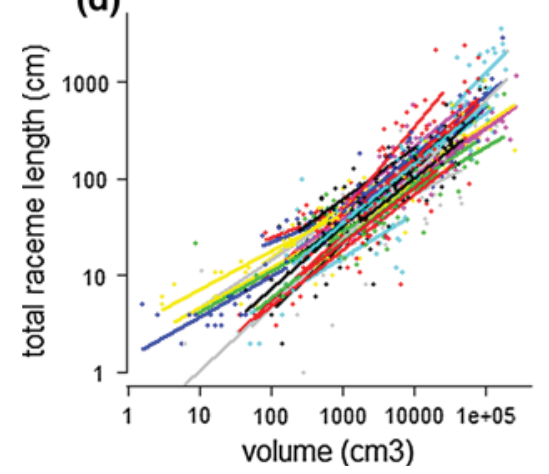

(e)

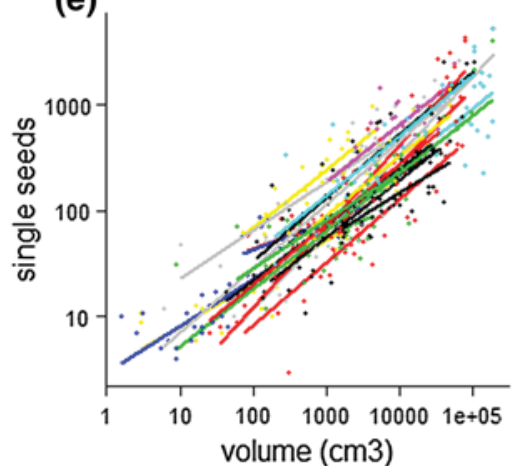

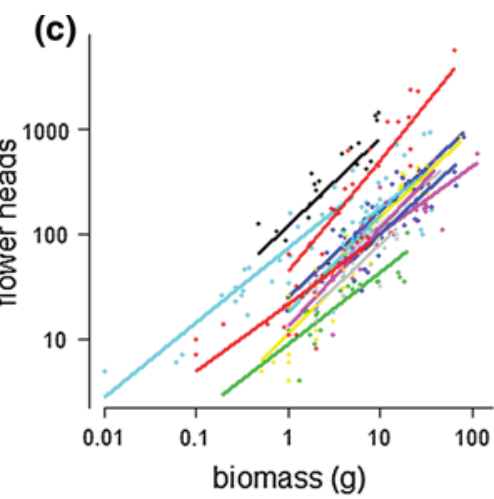

(f)

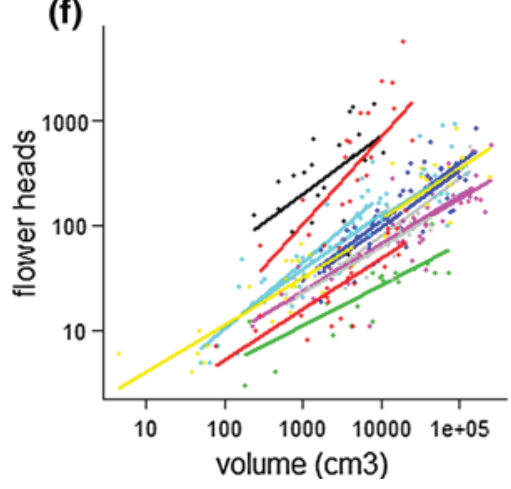

Fig. 2 Regressions of $\mathbf{a}, \mathbf{d}$ total raceme length (in $\mathrm{cm}$, a proxy for pollen production), and numbers of $\mathbf{b}, \mathbf{e}$ single seeds and $\mathbf{c}$, f female flower heads on $\mathbf{a}-\mathbf{c}$ dry biomass (in $\mathbf{g}$ ) or $\mathbf{d}-\mathbf{f}$ plant volume in $\left(\mathrm{cm}^{3}\right)$, on a $\log -\log$ scale, with site as random effect.

Chmielewska and Piotrowska (2008)]; and $m$ is the multiplier 4 to scale pollen estimates per plot up to estimates per $\mathrm{m}^{2}$. We similarly used the formula seeds $=d * f * v * s * m$, where $s$ is the fitted sitespecific number of single seeds produced per unit volume as predicted by the linear regression model of female structures on volume.

To assess the effect of habitat type, we constructed linear mixed effect models with the log-transformed density of pollen or seeds per plot as the response variable. We used the same subset of 36 sites used in the environmental models of plant volume. Besides habitat type we included all other environmental factors of the regional and site level (see "Models of plant volume" section) as fixed effects, and site was included as random effect on the intercept. Models were fitted with an Identity link function with Gaussian error distribution and Maximum Likelihood, after which we applied a stepwise model selection by AIC
Dots represent observed values of individual plants and lines the back-transformed fitted regressions for each site since all analyses were performed on log-transformed variables

as described in "Models of plant volume" section. We then performed a post hoc Tukey test for pairwise differences between the habitat types.

To assess the effect of country, we constructed a similar mixed effect model with only country as fixed effect, using a sum contrast (where the average response across all countries is the base). We used data of all 39 sites. Estimates of countries were considered to deviate significantly from average when their confidence interval did not overlap this average.

\section{Results}

Size-dependent reproduction

Total raceme length (a proxy for pollen production) and seed production per plant were to a very large extent determined by plant size, while sites differed in 
Table 2 Comparison of all models used to explain variation in the volume of individual plants

\begin{tabular}{lrlllrcc}
\hline Model & $\boldsymbol{d} \boldsymbol{f}$ & $\mathbf{R M S E}$ & \multicolumn{1}{l}{ logLik } & \multicolumn{1}{l}{ AIC } & \multicolumn{1}{c}{$\boldsymbol{\Delta \text { AIC }}$} & Marginal $\boldsymbol{R}^{\mathbf{2}}$ & Conditional $\boldsymbol{R}^{\mathbf{2}}$ \\
\hline TotalReduced & 11 & 1.802 & -5870.2 & 11764.4 & 0.0 & 0.273 & 0.648 \\
PlotReduced & 6 & 1.904 & -5880.0 & 11774.1 & 9.7 & 0.042 & 0.634 \\
Total & 19 & 1.784 & -5867.2 & 11774.4 & 10.0 & 0.321 & 0.656 \\
Plot & 7 & 1.905 & -5880.0 & 11775.9 & 11.5 & 0.042 & 0.635 \\
SiteReduced & 11 & 1.869 & -5882.1 & 11788.3 & 23.9 & 0.246 & 0.678 \\
RegionalReduced & 4 & 1.936 & -5889.2 & 11788.4 & 24.0 & 0.080 & 0.672 \\
Site & 12 & 1.854 & -5881.4 & 11788.8 & 24.4 & 0.262 & 0.679 \\
Regional & 6 & 1.932 & -5888.9 & 11791.7 & 27.3 & 0.088 & 0.672 \\
Null & 3 & 1.988 & -5892.2 & 11792.4 & 28.0 & 0.000 & 0.674 \\
\hline
\end{tabular}

All models include a random effect of plots nested within site. The regional, site and plot model each include a different set of environmental variables as fixed effect as indicated in Table 1, and the total model includes all of them. The reduced models (shaded) are those after stepwise model selection in both forward and backward direction, based on AIC. The null model only includes the random effects

the intercept and slope of these relationships (Fig. 2). Although plant biomass and volume were tightly correlated (Pearson correlation $=0.996$ ), plant biomass alone performed better than plant volume in explaining variation in raceme length (82 vs. $74 \%$ respectively) and seed production (74 vs. 59\% respectively). With respect to seed production, there seems to be more variation between sites in the number of flower heads (Fig. 2c, f) than in the number of single seeds (Fig. 2b, e). Considering the random effect of sites raised the explained variation of all models to $85-91 \%$ (Table S2). Since only plant volume had been measured for plants in plots, we used the corresponding models on plant volume including the random effect of site for the consecutive analyses on pollen and seed densities later on.

\section{Drivers of plant volume}

Seventeen percent of all 4438 tagged plants died before having matured when checked at the time of seed set. Of the remaining ones, $96.5 \%$ had matured. The volume of a total of 3412 plants in 457 plots in the 39 populations was recorded (see number of plots with plants measured per site in Table 1). Most of all the variation in these plant volumes was related to differences between sites $(53.5 \%$, average plant volume per site is indicated in Table 1) but plots within sites also contributed to variation $(13.7 \%)$, while the remaining $32.8 \%$ represented size variation between individual plants within plots.
The reduced, more parsimonious models fitted the data nearly as good as the full models (maximum $0.8 \%$ difference in conditional $\mathrm{R}^{2}$, Table 2 ). The environmental factors in the reduced site model explained more variation $\left(25 \%\right.$, marginal $\mathrm{R}^{2}$ in Table 2 ) than the reduced regional $(8 \%)$ and the reduced plot model (4\%). Not surprisingly, the reduced total model which included environmental factors from all spatial scales was better $(27 \%)$.

The total reduced model (Table 3, Table S3 for correlation coefficients of fixed effects) contained environmental factors of all spatial scales. At the regional level, altitude was correlated with smaller plant volumes (Fig. 3a). At the level of the site, weather and soil variables affected plant volume. Specifically, growing degree days were positively related with plant volume for high levels of precipitation, but negatively for low levels of precipitation (Fig. 3b). The fraction of sand was negatively related to plant volume (Fig. 3c). At the level of the plot, more bare soil (Fig. 3d), higher Ambrosia densities (Fig. 3e) and higher cover by other vegetation (Fig. 3f) were all negatively related with individual plant volume. The estimates of the environmental factors and the correlation coefficients of the three other reduced models are presented in Table S4-9.

\section{Patterns of pollen and seed densities}

Combining data on plant density and volume per plot, we found that the estimated pollen and seed 
(a)

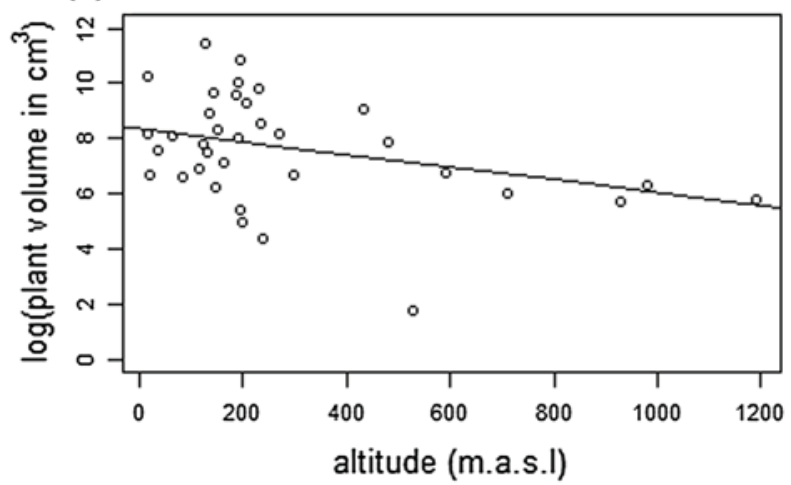

(c)

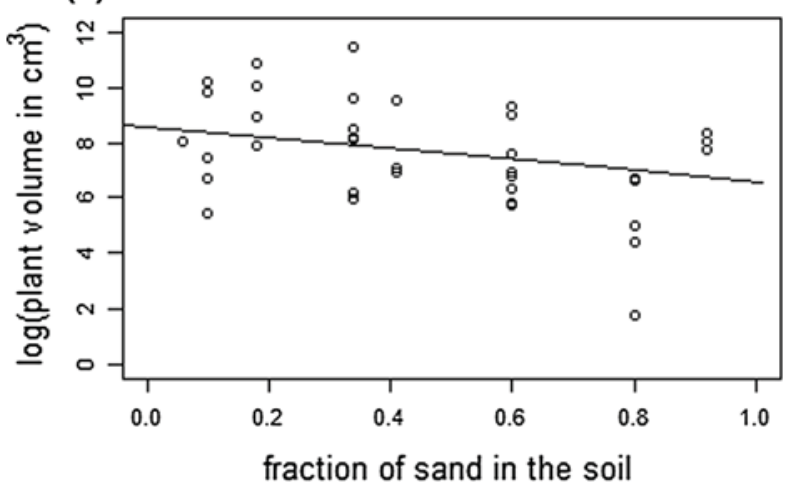

(e)

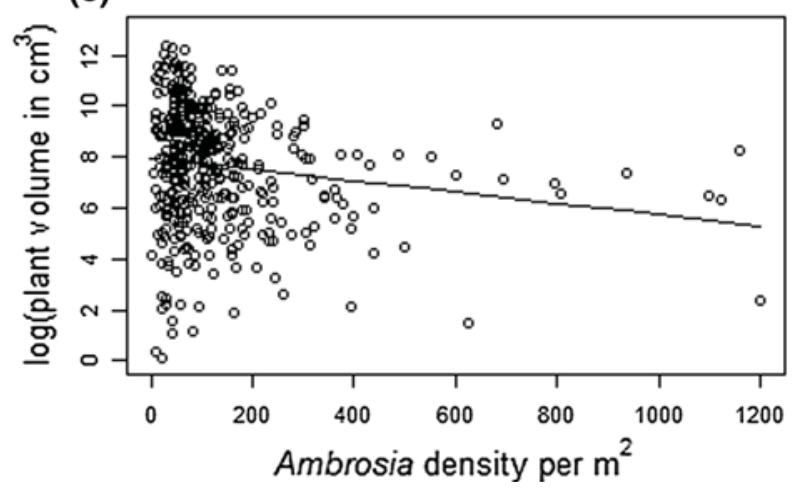

Fig. 3 Effects of different environmental factors on plant volume. Symbols represent observed values per site $(\mathbf{a}-\mathbf{c})$ or per plot within sites $(\mathbf{d}-\mathbf{f})$ with corresponding fitted regression lines. Panels present the effect of $\mathbf{a}$ altitude, $\mathbf{b}$ the interaction of growing degree days and precipitation (low $\leq 2.2 \mathrm{~mm} /$ day,

production per $\mathrm{m}^{2}$ varied dramatically between sites (Fig. S1). A Romanian site produced the maximum number of $104 * 10^{9}$ pollen per $\mathrm{m}^{2}$, and a Croatian the maximum amount of $67 * 10^{3}$ seeds per $\mathrm{m}^{2}$, which was, respectively, 238-fold and 175-fold of those at (b)

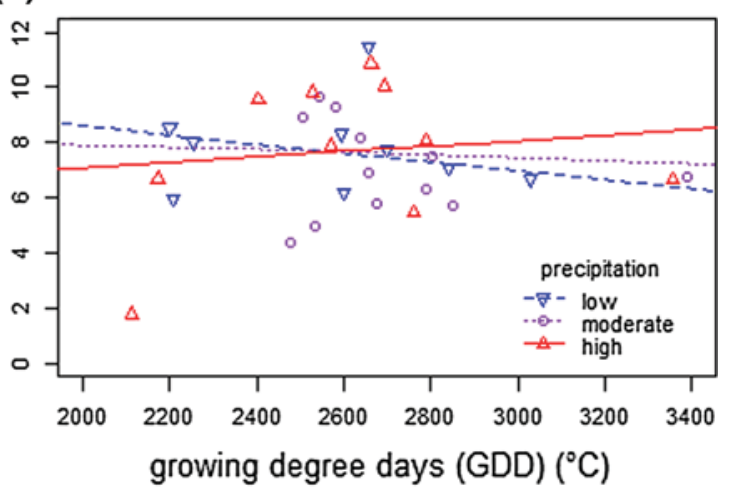

(d)

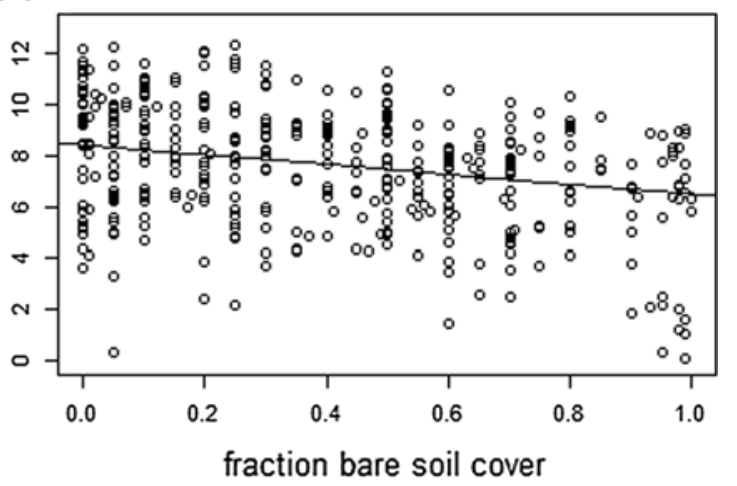

(f)

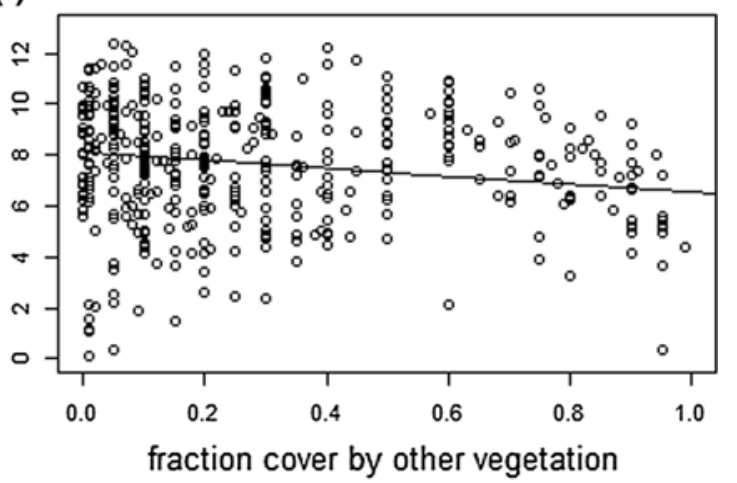

moderate $=2.2-2.7 \mathrm{~mm} /$ day, high $\geq 2.7 \mathrm{~mm} /$ day), $\mathbf{c}$ the fraction of sand in the soil, $\mathbf{d}$ the fraction of bare soil, e Ambrosia density, and $\mathbf{f}$ the fraction of soil in the plot covered by vegetation other than Ambrosia

one of the Swiss sites with lowest values of all sites. Comparing countries, sites in Croatia, Hungary and Romania generally produced more than average (Fig. 4). 
(a)

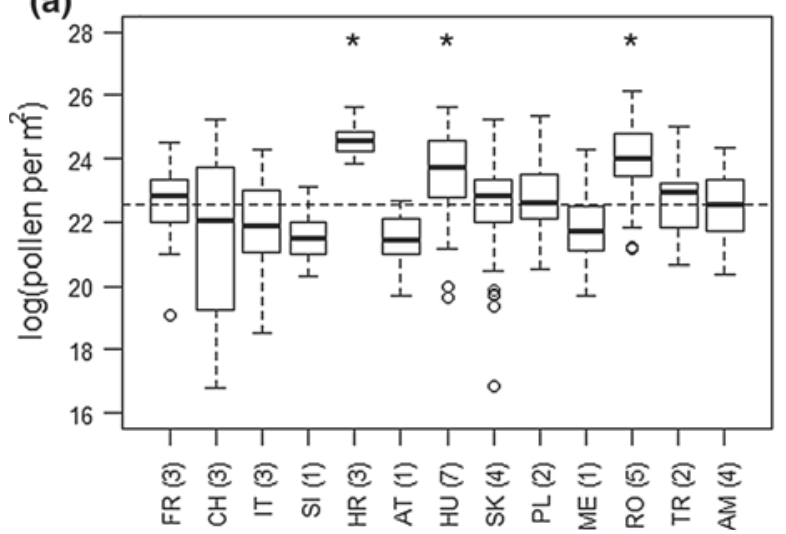

Fig. 4 Estimated amounts of $\mathbf{a}$ pollen and $\mathbf{b}$ seeds produced per $\mathrm{m}^{2}$ per country ordered by longitude (FR France, $\mathrm{CH}$ Switzerland, IT Italy, SI Slovenia, HR Croatia, AT Austria, $H U$ Hungary, $S K$ Slovakia, $P L$ Poland, $M E$ Montenegro, $R O$ Romania, $T R$ Turkey, $A M$ Armenia). Numbers of sites per country are indicated below the labels. Boxplots represent the

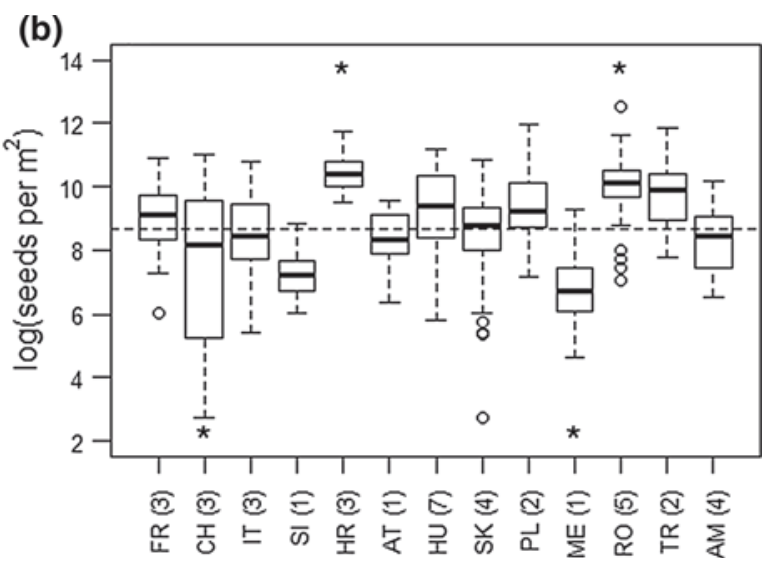

variation across plots within sites, with the thick line as the median, the boxes representing the quartiles, and the whiskers 1.5 times the interquartile range, and dots data points outside the whiskers. Asterisks indicate countries whose production significantly deviates from the overall average

Table 3 Effect of all environmental factors of the best model ("Total Reduced") on individual plant volume

\begin{tabular}{llrrrrr}
\hline Environmental factor & Scale & Estimate & SE & $d f$ & $t$ value & $p$ value \\
\hline (Intercept) & & 7.664 & 0.219 & 2609 & 34.930 & 0.000 \\
Altitude & Regional & -0.621 & 0.215 & 30 & -2.883 & 0.007 \\
Fraction sand & Site & -0.538 & 0.226 & 30 & -2.383 & 0.024 \\
GDD & Site & 0.044 & 0.220 & 30 & 0.200 & 0.843 \\
Precipitation & Site & 0.099 & 0.216 & 30 & 0.461 & 0.648 \\
GDD $\times$ precipitation & Site & 0.712 & 0.283 & 30 & 2.515 & 0.018 \\
bare soil & Plot & -0.602 & 0.131 & 379 & -4.588 & 0.000 \\
Ambrosia density & Plot & -0.296 & 0.070 & 379 & -4.249 & 0.000 \\
Other vegetation & Plot & -0.415 & 0.117 & 379 & -3.548 & 0.000 \\
\hline
\end{tabular}

The generalised linear mixed-effects model included all environmental variables remaining after stepwise AIC-based selection of factors. Scale represents the spatial scale of the environmental variable; Estimates represent coefficients of $\log$ (plant volume in $\mathrm{cm}^{3}$ ) with their SE; the $t$ value is the ratio between the estimate and its SE, and the $p$ value the probability that this $t$-statistic is drawn from a standard $t$-distribution with " $d f$ " degrees of freedom

The environmental models of pollen (Table S1011) and seed densities (Table S12-13) obtained after stepwise AIC selection were significantly better than their respective null models (both L-ratio $=27$, $p<0.01$ ), and both contained the effect of habitat type. Ruderal sites produced the lowest densities, significantly less pollen than arable sites (Fig. 5a, Table S11), and significantly less seeds than sites along infrastructure (Fig. 5b, Table S13). Effects of altitude and the interaction between GDD and precipitation were similar in models of pollen and seeds (Table S11, S13) as those found in the model of plant volume (Table 3). The model of seeds included factors not found in the model of plant volume: latitude and the presence of Ophraella were negatively related to the density of seeds produced (Table S13).

\section{Discussion}

We established that plant volume measured in the field serves well as a proxy for total raceme length (related to pollen production) and seed production, in line with Fumanal et al. (2007a). Plant volume can easily be 
(a)

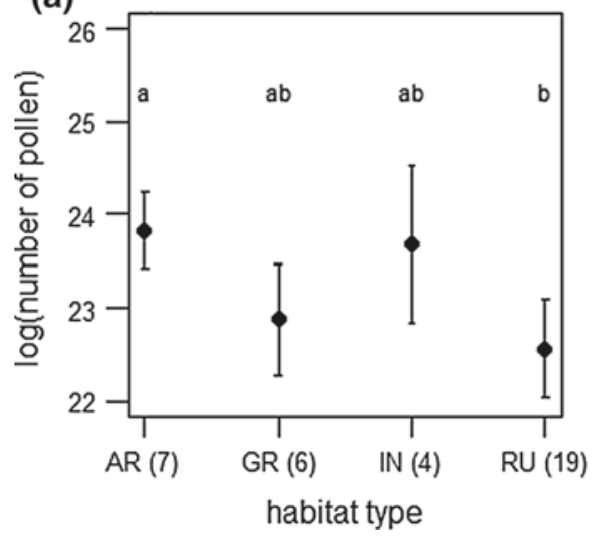

Fig. 5 Estimated amounts of $\mathbf{a}$ pollen and $\mathbf{b}$ seeds produced per $\mathrm{m}^{2}$ per habitat type ( $A R$ arable, $G R$ grassland, $I N$ infrastructure, $R U$ ruderal). Numbers of site per habitat are indicated in brackets. Boxplots represent the variation across plots within

measured in the field, and is hence a practical predictor. In contrast to Fumanal et al. (2007a), we found plant dry biomass to be an even better predictor which should hence be favoured if destructive sampling is possible. For the study of demographic performance of undisturbed populations this destructive measure is less suitable. Either of these size measures explained more variation in raceme length and seed production than site identity. This highlights the relevance of assessing individual plant size for estimates of total local pollen and seed production, and the necessity of a large sample of plant sizes per site. We found, however, the precise relationship between size and reproductive measures to be site-specific, indicating that very precise estimates of pollen and seed production require assessing this relationship at the level of the site.

Most of the variation in A. artemisiifolia plant volume stemmed from variation among sites, although a remarkable amount of variation existed between individuals within plots within sites. Variation in plant size of A. artemisiifolia was previously found in field surveys in smaller geographical areas (Fumanal et al. 2007a, 2008; Ortmans et al. 2016), but our study shows that variation across sites (rather than across regions) is also the most important spatial level when examined across the entire European distribution of the species. Local conditions and not regional gradients were also found to drive demographic variation in two closely related species, Ambrosia trifida and Helianthus аппииs, on corn fields in the US (Wortman (b)

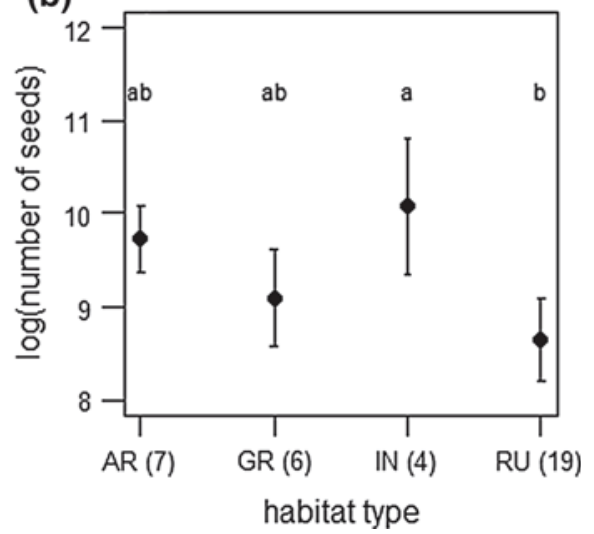

sites, with the thick line as the median, the boxes representing the quartiles, and the whiskers 1.5 times the interquartile range, and dots data points outside the whiskers. Habitat types with similar letters do not significantly differ in their production

et al. 2012). Spatial variation in plant volume of $A$. artemisiifolia was best explained, however, by combining explanatory information from all levels (i.e. regions, site and plot; Table 3).

The most important factors at the local scale determining plant volume were the weather (the interaction between temperature and precipitation), and soil type. Higher temperatures resulted in larger plants at high levels of precipitation, but not at low or intermediate levels of precipitation. This is in line with experimental work where A. artemisiifolia growth aboveground was increased by elevated temperature and water supply (Deen et al. 1998; Leskovsek et al. 2012b; Skálová et al. 2015), and with reduced growth in response to drought found in a field experiment (Leiblein and Loesch 2011). This result is also consistent with poor climatic suitability in Mediterranean regions due to summer drought stress (Essl et al. 2015). It is the first time that a relation between size of A. artemisiifolia and the fraction of sand in the soil is found. Ambrosia artemisiifolia is known to occur in many soil types and laboratory experiments have not revealed effects of soil type so far (Onen et al. 2017).

Our field survey also identified effects at the scale of the neighbouring vegetation on A. artemisiifolia plant volume, confirming the negative effects of interspecific and intraspecific plant competition found earlier by experimentation (Leskovsek et al. 2012a, b; MacDonald and Kotanen 2010; Patracchini et al. 2011). This result is in accordance with the process of 
biotic resistance (Levine et al. 2004) and supports the idea of competitive vegetation as a control method for annual invaders such as $A$. artemisiifolia (Gentili et al. 2015). Our study, however, outlines the importance of local conditions in determining the volume of $A$. artemisiifolia independent of vegetation cover. For management through interspecific competition it would therefore be relevant to assess potential interactions between habitat and vegetation cover. It seems contradictory that we also found a negative effect of bare soil on the volume of A. artemisiifolia. This may be explained by the fact that 'bare soil' included litter (which reduces early plant growth), rocks, or that high values of bare soil could reflect lower quality spots (i.e. stronger abiotic constraints) resulting in less plant growth in general. At the regional scale, altitude was related to smaller plant volumes. As models also included the GDD, this suggests that other conditions of sites at altitudes than lower temperatures reduce plant volume.

Overall, several a priori suspected environmental factors were indeed shown to affect individual $A$. artemisiifolia plant volume in our field populations. We confirmed the relevance of all factors that were previously identified in experimental work (GDD, precipitation, vegetation cover, Ambrosia density), except for latitude. Our study provided insight in the relative importance of these factors, which are often tested individually in experimental settings. For instance, the neighbouring vegetation and bare soil largely influenced plant volume given the local conditions (Table 3), but these variables alone only explained little (4\%, Table 2). We found no support for effects of other factors that were based on nonexperimental literature (habitat type, the presence of Ophraella, and light competition). The effect of habitat type and Ophraella may not have been detected due to the lack of a full factorial design, while our method of scoring light competition likely yielded too little variation.

The large unexplained variation in A. artemisiifolia volume between individuals within plots is likely to be the result of differential timing of seedling emergence, and potentially from large intra-population genetic variation that is typical of invasive populations of $A$. artemisiifolia (Gallien et al. 2016; Gaudeul et al. 2011; Genton et al. 2005). Our study focussed on spatial variation, but we acknowledge that temporal variation in the environment plays an important role in variation in plant performance in an annual species. Environmental drivers such as weather and vegetation cover vary temporally. We therefore expect the volume of $A$. artemisiifolia plants to also vary from year to year and to change with vegetation succession. In addition, populations of $A$. artemisiifolia may adapt to the environment over evolutionary time. Previous studies found that phenotypic plant traits of A. artemisiifolia change with the residence time of populations (Fenesi and Botta-Dukat 2012) and adaptations to frost (Leiblein-Wild et al. 2014), shorter day length (Leiblein-Wild and Tackenberg 2014), and lower temperatures at higher elevations (Gallien et al. 2016) have already been detected in Europe. Unfortunately, the invasion history of most of our sites was unknown.

Total numbers of pollen and seed produced locally depend on the abundance, density and size of $A$. artemisiifolia. Lacking accurate data on abundance at the scale of sites or regions, we used the density and volume of $A$. artemisiifolia to estimate pollen and seed production per square meter land, and assessed how much these vary between our selected habitat types and European countries. Ruderal sites produced lowest densities of pollen and seeds (Fig. 5). This may partially be explained by a relatively high fraction of bare soil in this habitat (Fig. S2) reducing plant size. Arable land produced higher densities of pollen, in line with earlier findings from France (Fumanal et al. 2007a), emphasizing the need for controlling populations of A. artemisiifolia on (ex-)arable land from a health perspective, too. Sites along infrastructures produced higher densities of seeds, emphasizing the importance for management along road sides and railways, which are a main source for dispersal of seeds (Chapman et al. 2016). The analysis also revealed the negative effect of altitude on pollen and seed densities (Table S10), maybe because altitude strongly reduces plant size (Fig. 3a). Interestingly, the leaf beetle Ophraella was also associated with lower seed densities produced (Table S10), which might be explained by lower A. artemisiifolia densities resulting from seedling mortality (Lommen et al., personal observations). This is promising from the perspective of biological control, but assessing the potential impact of this biological control agent requires data on the impact at the population level (Hahn et al. 2012; Morin et al. 2009).

The top-3 of countries with highest densities of pollen and seeds produced consisted of Croatia, 
Romania and Hungary. Despite the small number of sites per country, our results are in line with the fact that highest annual amounts of airborne pollen are recorded on the Pannonian Plain, which includes these countries and is highly infested with $A$. artemisiifolia (Sikoparija et al. 2017). We had expected low densities of pollen in Italy, where all sites are located on the Po Plain and are colonised by the Ophraella beetle. Although the Po Plain is one of the major areas infested with A. artemisiifolia in Europe (Essl et al. 2015), pollen numbers have dramatically decreased in this area since the Ophraella beetle was detected in 2013 (Bonini et al. 2015). Italy was among the countries with low pollen densities but its numbers were not significantly different from average.

We recognise that our study is an observational one and that correlations found do not necessary reflect a causal relationship, even though many results corroborate earlier experimental work. In addition, the set of study sites included in this study is influenced by the local legislation regarding management of A. artemisiifolia (in some regions it was not allowed to leave populations unmanaged for the study), the availability of local researchers, and the local prevalence of infested habitat and soil types, therefore not complying with a full factorial design. We also acknowledge that our results only apply to undisturbed, unmanaged sites, and that management can greatly affect plant growth, pollen and seed production, as has been demonstrated for mowing regimes (Milakovic et al. 2014; Simard and Benoit 2011).

\section{Conclusions and outlook}

Our study shows that per-capita pollen and seed production can be predicted well from plant volume data in the field and that variation in plant volume depends mainly on the local environment. We also found that densities of pollen and seed production per surface area vary with habitat type. These results imply that the effort needed for management interventions of $A$. artemisiifolia cannot be generalised to a regional scale, but should be adapted to the local conditions. This is the first field study that identifies local environmental drivers related to individual performance of $A$. artemisiifolia in the field, which may help to prioritise management based on such local conditions. Spatial models of airborne A. artemisiifolia pollen (Karrer et al. 2015; Skjoth et al. 2010) could also be refined by including the environmental drivers we identified using corresponding environmental filters with a high local resolution. To assess the long-term pollen and seed production of populations of A. artemisiifolia, however, we need to understand the effect of environmental factors on all demographic vital rates, including establishment and survival rates of plants over summer and the long-term survival rate of seeds in the soil seed bank.

Acknowledgements This study was coordinated within the framework of the EU COST Action FA1203 "Sustainable management of Ambrosia artemisiifolia across Europe (SMARTER)" (Müller-Schärer and Lommen 2014). The SMARTER Task Force "Population Dynamics" was initiated to study natural variation in the demography of A. artemisiifolia across the European continent. This allowed collecting labourintensive data at a large geographic scale, exceeding the capacity of individuals groups (Colautti et al. 2014). For the coordination of the work, we acknowledge financial support from the Swiss State Secretariat for Education, Research and Innovation (C13.0146 to HMS and STEL), the Swiss Federal Office for the Environment (13.0098.KP/M323-0760 to HMS) and that for Agriculture (1062-62,200 to HMS), the EU COST Action FA1203 'Sustainable management of Ambrosia artemisiifolia in Europe (SMARTER)', and the Netherlands Organisation for Scientific Research (NWO-grants 840.11.001/841.11.007 to $\mathrm{CAH}$ and EJ). We thank Carsten Skjøth for providing all weather data, Yan Sun for data on occurrences of $A$. artemisiifolia for the bioclimatic analysis, Olivier Brönnimann for help with the latter, Daniel Chapman for sources on Ambrosia abundance, and Rudolf Rohr for statistical advice. We acknowledge the support of the many local funding bodies and we are grateful to all those who made this research possible locally: people that organised sites, land owners and managers, and not least tens of people that helped in collecting data. An extensive list of local funding bodies and people acknowledged is provided in the Electronic Supplementary Information.

\section{References}

Bonini M, Sikoparija B, Prentovic M et al (2015) A follow-up study examining airborne Ambrosia pollen in the Milan area in 2014 in relation to the accidental introduction of the ragweed leaf beetle Ophraella communa. Aerobiologia 32:371-374

Buttenschøn RM, Waldispühl S, Bohren C (2009) Guidelines for management of common ragweed, Ambrosia artemisiifolia. University of Copenhagen, Copenhagen

Chapman DS, Haynes T, Beal S et al (2014) Phenology predicts the native and invasive range limits of common ragweed. Glob Change Biol 20:192-202

Chapman DS, Makra L, Albertini R et al (2016) Modelling the introduction and spread of non-native species: international trade and climate change drive ragweed invasion. Glob Change Biol 22:3067-3079 
Colautti RI, Franks SJ, Hufbauer RA et al (2014) The Global Garlic Mustard Field Survey (GGMFS): challenges and opportunities of a unique, large-scale collaboration for invasion biology. NeoBiota 21:29-47

Cunze S, Leiblein MC, Tackenberg O (2013) Range expansion of Ambrosia artemisiifolia in Europe is promoted by climate change. ISRN Ecol 2013:1-9

Déchamp C, Méon H, Reznik SY (2009) Ambrosia artemisiifolia L. an invasive weed in Europe and adjacent countries: the geographical distribution (except France) before 2009. In: Déchamp C, Méon H (eds) AMBROISIE: the first international ragweed review. Association Française d'Etude des Ambroisies (AFEDA), Saint-Priest, pp 24-46

Deen W, Hunt T, Swanton CJ (1998) Influence of temperature, photoperiod, and irradiance on the phenological development of common ragweed (Ambrosia artemisiifolia). Weed Sci 46:555-560

Essl F, Biró K, Brandes D et al (2015) Biological flora of the British Isles: Ambrosia artemisiifolia. J Ecol 103:10691098

Fenesi A, Botta-Dukat Z (2012) Phenotypic divergences induced by different residence time in invasive common ragweeds. J Plant Ecol 5:174-181

Fenesi A, Albert Á-J, Ruprecht E (2014) Fine-tuned ability to predict future competitive environment in Ambrosia artemisiifolia seeds. Weed Res 54:58-69

Fumanal B, Chauvel B, Bretagnolle F (2007a) Estimation of pollen and seed production of common ragweed in France. Ann Agric Environ Med 14:233-236

Fumanal B, Chauvel B, Sabatier A et al (2007b) Variability and cryptic heteromorphism of Ambrosia artemisiifolia seeds: What consequences for its invasion in France? Ann Bot 100:305-313

Fumanal B, Girod C, Fried G et al (2008) Can the large ecological amplitude of Ambrosia artemisiifolia explain its invasive success in France? Weed Res 48:349-359

Gallien L, Thuiller W, Fort N et al (2016) Is there any evidence for rapid, genetically-based, climatic niche expansion in the invasive common ragweed? PLoS ONE 11:e0152867

Gaudeul M, Giraud T, Kiss L et al (2011) Nuclear and chloroplast microsatellites show multiple introductions in the worldwide invasion history of common ragweed, Ambrosia artemisiifolia. PLoS ONE 6:e17658

Gentili R, Gilardelli F, Ciappetta S et al (2015) Inducing competition: intensive grassland seeding to control Ambrosia artemisiifolia. Weed Res 55:278-288

Genton BJ, Shykoff JA, Giraud T (2005) High genetic diversity in French invasive populations of common ragweed, $\mathrm{Am}$ brosia artemisiifolia, as a result of multiple sources of introduction. Mol Ecol 14:4275-4285

Hahn MA, Buckley YM, Mueller-Schaerer H (2012) Increased population growth rate in invasive polyploid Centaurea stoebe in a common garden. Ecol Lett 15:947-954

Hamaoui-Laguel L, Vautard R, Liu L et al (2015) Effects of climate change and seed dispersal on airborne ragweed pollen loads in Europe. Nat Clim Change 5:766-771

Jongejans E, Jorritsma-Wienk LD, Becker U et al (2010) Region versus site variation in the population dynamics of three short-lived perennials. J Ecol 98:279-289

Karrer G, Milakovic M, Kropf M et al (2011) Dispersal and management of a highly allergenic introduced plant- pathways and causes for the dispersal of ragweed ( $\mathrm{Am}$ brosia artemisiifolia) and options for control. BMLFUW, Vienna, p 329

Karrer G, Skjoth CA, Sikoparija B et al (2015) Ragweed (Ambrosia) pollen source inventory for Austria. Sci Total Environ 523:120-128

Kazinczi G, Béres I, Novák R et al (2008) Common ragweed (Ambrosia artemisiifolia): a review with special regards to the results in Hungary. I. Taxonomy, origin and distribution, morphology, life cycle and reproduction strategy. Herbologia 9:55-92

Kazinczi G, Béres I, Novák R et al (2009) Focusing again on common ragweed (Ambrosia artemisiifolia L.). Növényvédelem 45:389-403 (in Hungarian)

Leiblein MC, Loesch R (2011) Biomass development and $\mathrm{CO}_{2}$ gas exchange of Ambrosia artemisiifolia L. under different soil moisture conditions. Flora 206:511-516

Leiblein-Wild MC, Tackenberg O (2014) Phenotypic variation of 38 European Ambrosia artemisiifolia populations measured in a common garden experiment. Biol Invasions 16:2003-2015

Leiblein-Wild MC, Kaviani R, Tackenberg O (2014) Germination and seedling frost tolerance differ between the native and invasive range in common ragweed. Oecologia 174:739-750

Leskovsek R, Datta A, Simoncic A et al (2012a) Influence of nitrogen and plant density on the growth and seed production of common ragweed (Ambrosia artemisiifolia L.). J Pest Sci 85:527-539

Leskovsek R, Eler K, Batic F et al (2012b) The influence of nitrogen, water and competition on the vegetative and reproductive growth of common ragweed (Ambrosia artemisiifolia L.). Plant Ecol 213:769-781

Levine JM, Adler PB, Yelenik SG (2004) A meta-analysis of biotic resistance to exotic plant invasions. Ecol Lett 7:975-989

Lommen S, Jolidon E, Bustamante Eduardo J et al (2017) An early suitability assessment of two exotic Ophraella species (Coleoptera: Chrysomelidae) for biological control of invasive ragweed in Europe. Eur J Entomol 114:160-169

MacDonald AAM, Kotanen PM (2010) The effects of disturbance and enemy exclusion on performance of an invasive species, common ragweed, in its native range. Oecologia 162:977-986

Milakovic I, Fiedler K, Karrer G (2014) Management of roadside populations of invasive Ambrosia artemisiifolia by mowing. Weed Res 54:256-264

Morin L, Reid AM, Sims-Chilton NM et al (2009) Review of approaches to evaluate the effectiveness of weed biological control agents. Biol Control 51:1-15

Müller-Schärer H, Lommen S (2014) EU-COST Action on "Sustainable management of Ambrosia artemisiifolia in Europe" (COST FA1203-SMARTER): opportunities and challenges. Julius-Kühn-Archiv 445:148-155

Müller-Schärer H, Lommen STE, Rossinelli $\mathrm{M}$ et al (2014) Ophraella communa, the ragweed leaf beetle, has successfully landed in Europe: fortunate coincidence or threat? Weed Res 54:109-119

Naimi B (2015) Uncertainty analysis for species distribution models. https://cran.r-project.org/web/packages/usdm/ index.html. Accessed 01 June 2016 
Nakagawa S, Schielzeth H (2013) A general and simple method for obtaining $\mathrm{R}^{2}$ from generalized linear mixed-effects models. Methods Ecol Evol 4:133-142

Onen H, Farooq S, Gunal H et al (2017) Higher tolerance to abiotic stress and soil types may accelerate common ragweed (Ambrosia artemisiifolia) invasion. Weed Sci 65:115-127

Ortmans W, Mahy G, Chauvel B et al (2016) Performance variation of common ragweed (Ambrosia artemisiifolia $\mathrm{L}$.) across invasion levels in Western Europe. Flora 220:134-141

Patracchini C, Vidotto F, Ferrero A (2011) Common ragweed (Ambrosia artemisiifolia) growth as affected by plant density and clipping. Weed Technol 25:268-276

Pauchard A, Shea K (2006) Integrating the study of non-native plant invasions across spatial scales. Biol Invasions 8:399-413

R Core Team (2014) R: a language and environment for statistical computing. R Foundation for Statistical Computing. http://www.R-project.org/. Accessed 01 June 2015

Richardson DM, Pyšek P (2012) Naturalization of introduced plants: ecological drivers of biogeographical patterns. New Phytol 196:383-396

Sikoparija B, Skjøth CA, Celenk S et al (2017) Spatial and temporal variations in airborne Ambrosia pollen in Europe. Aerobiologia 33:181-189

Simard M-J, Benoit DL (2011) Effect of repetitive mowing on common ragweed (Ambrosia artemisiifolia L.) pollen and seed production. Ann Agric Environ Med 18:55-62

Skálová H, Moravcová L, Dixon AFG et al (2015) Effect of temperature and nutrients on the growth and development of seedlings of an invasive plant. AoB Plants 7:plv044. https://doi.org/10.1093/aobpla/plv044
Skjoth CA, Smith M, Sikoparija B et al (2010) A method for producing airborne pollen source inventories: an example of Ambrosia (ragweed) on the Pannonian Plain. Agric For Meteorol 150:1203-1210

Smith M, Cecchi L, Skjoth CA et al (2013) Common ragweed: a threat to environmental health in Europe. Environ Int 61:115-126

Traveset A, Brundu G, Carta L et al (2008) Consistent performance of invasive plant species within and among islands of the Mediterranean basin. Biol Invasions 10:847-858

Venables WN, Ripley BD (2002) Modern applied statistics with S. Springer, New York

Vitalos M, Karrer G (2009) Dispersal of Ambrosia artemisiifolia seeds along roads: the contribution of traffic and mowing machines. In: Pyšek P, Pergl J (eds) Biological invasions: towards a synthesis, proceedings Neobiota, vol 8. pp 53-60

von der Lippe M, Bullock JM, Kowarik I et al (2013) Humanmediated dispersal of seeds by the airflow of vehicles. PLoS ONE 8:e52733

Weryszko-Chmielewska E, Piotrowska K (2008) Ecological features of Ambrosia artemisiifolia L. flowers and characteristics of Ambrosia L. pollen seasons in the condition of Lublin (Poland) in the years 2001-2008. Acta Agrobot 61:35-47

Wortman SE, Davis AS, Schutte BJ et al (2012) Local conditions, not regional gradients, drive demographic variation of giant ragweed (Ambrosia trifida) and common sunflower (Helianthus annuus) across northern U.S. maize belt. Weed Sci 60:440-450

Zhou ZS, Chen HS, Zheng XW et al (2014) Control of the invasive weed Ambrosia artemisiifolia with Ophraella communa and Epiblema strenuana. Biocontrol Sci Technol 24:950-964 